九州大学学術情報リポジトリ

Kyushu University Institutional Repository

\title{
ON THE HOMOLOGY OF THE THORACIC AND ABDOMINAL AREAS OF THE WEEVIL LARVAE AS BASED ON A STUDY OF THE MUSCLES (COLEOPTERA : CURCULIONOIDEA)
}

Morimoto, Katsura

Entomological Laboratory, Faculty of Agriculture, Kyushu University

Lee, Chan-Young

Entomological Laboratory, Faculty of Agriculture, Kyushu University

https://doi.org/10.5109/2497

出版情報: ESAKIA. 25，pp.141-148，1987-01-31. Entomological Laboratory，Faculty of Agriculture, Kyushu University

バージョン：

権利関係 : 


\title{
ON THE HOMOLOGY OF THE THORACIC AND ABDOMINAL AREAS OF THE WEEVIL LARVAE AS BASED ON A STUDY OF THE MUSCLES (COLEOPTERA : CURCULIONOIDEA)*
}

\author{
Katsura Morimoto and Chan- Young L E E \\ Entomological Laboratory, Faculty of Agriculture, \\ Kyushu University, Fukuoka 812, Japan
}

\begin{abstract}
The thoracic and abdominal areas of the weevil larvae are defined by their muscles. New interpretations are given to the tergal folds from a viewpoint of phylogeny. The alar and spiracular areas of the thorax are newly interpreted.
\end{abstract}

Weevil larvae of the superfamily Curculionoidea are generally legless grubs of the brownish head capsules and whitish bodies. Their body consists of three segments in the thorax and ten segments in the abdomen, and each segment is subdivided into several plicae by delicate sulci.

First attempt was made by Böving and Craighead (1931) to separate the superfamily Curculionoidea into families on the mode of the subdivision of body segments in the larvae, and systematic value of the tergal folds in the larvae was discussed by Emden (1938). The terminology for the systematics of the weevil larvae was reviewed by Anderson (1947) to make a standard for the description. But, these studies are partly insufficient for the phylogenetic study, because they observed the larvae externally and confused the thoracic and abdominal areas in some cases.

The purpose of this paper is to establish a morphological foundation for the subsequent description and systematics of the Japanese weevil larvae based on a study of the muscles.

We express our gratitude to Prof. Y. Hirashima, Kyushu University, for his valuable suggestions in the preparation of this paper.

\section{Materials and methods}

The muscles of the following species are fully examined in detail and many of the other species are partly checked.

Araecerus fasciculatus (Anthribidae, Choraginae).

Exechesops leucopis (Anthribidae, Anthribinae).

Phialodes mifipennis (Attelabidae, Attelabini).

Apoderus nitens (Attelabidae, Apoderini).

Mechoris ursulus (Attelabidae, Rhynchitini).

Byctiscus venustus (Attelabidae, Byctiscini).

Apion (Piezotrachelus) japonicum (Apionidae, Apionini).

* Contribution from the Entomological Laboratory, Faculty of Agriculture, Kyushu University, Fukuoka (Ser. 3, No. 223). 
Episomusmundus (Curculionidae, Episomini).

Hyperabasalis (Curculionidae, Hyperini).

Cionushelleri (Curculionidae, Cionini),

Rhynchaenus horii (Curculionidae, Rhynchaenini).

Curculio den tipes (Curculionidae, Curculionini).

Shirahoshizorufescens (Curculionidae, Cryptorhynchini).

Dyscerus perforatus (Curculionidae, Hylobiini).

Myocalandra exarata (Rhynchophoridae, Sitophilini).

Tomicus piniperda (Scolytidae, Hylesininae).

Living larvae were killed by injecting the fixative (equivalent mixture of $95 \%$ alcohol and $30 \%$ formalin) from the latero-posterior part of the body so as to stretch the plicae and muscles, and preserved in alcohol. The larva was cut just into halves in the middle by a razor blade, and then the internal organs and fat-bodies were removed by fine forceps under stereoscopic microscope. The

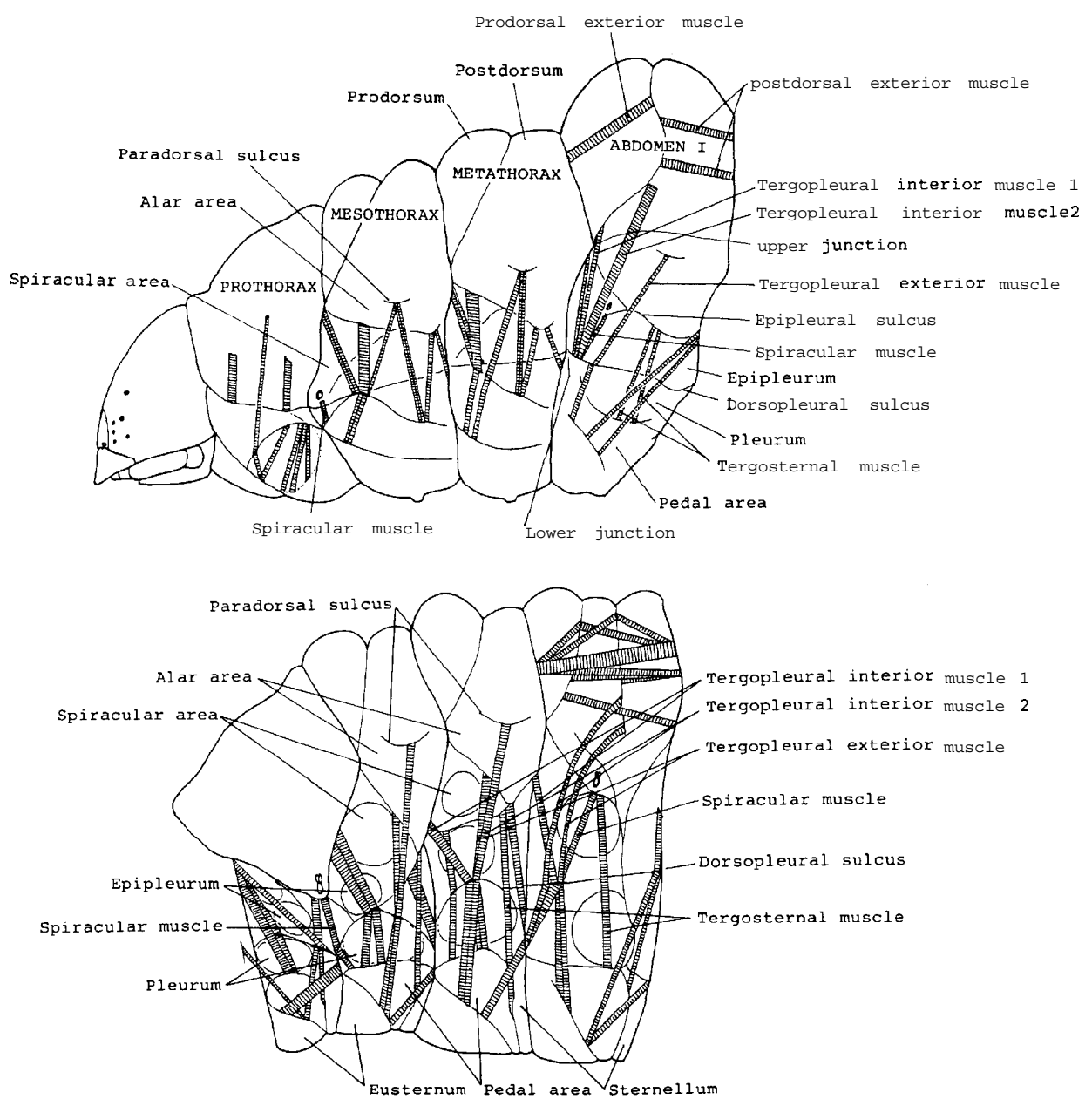

Fig. 1. The thoracic and abdominal areas and the lateral muscles. Above: Phialodes rufipennis (Attelabini). Below : Curculiodentipes (Curculionini). 
halves were stained with acetic fuchsin and the fat-bodies between muscles were carefully removed. The halves were put in water in a small dish and observed under stereoscopic microscope up to X 80 magnification.

\section{Results}

\section{The typical abdominal segments. \\ The tergum.}

The tergum with its areas is separated in all segments from the combined pleural and sternal regions by the dorsopleural sulcus throughout the entire length of body. This sulcus is easily determined by the attachments of the lateral muscles and oblique pleural muscle. In the abdominal segments, two tergopleural interior muscles originate from the fragmata at the anterior part of the dorsopleural sulcus, and inserted one to the upper junction and the other obliquely to the postdorsal sulcus. The spiracular muscle and the tergopleural exterior muscle originate also from the same fragmata and the former is inserted into the base of spiracle and the latter is to the paradorsal sulcus.

The tergum is subdivided into the dorsum, epipleurum and spiracular area according to Anderson (1947), and the dorsum is subdivided into two to three or four folds by transverse sulci.

The dorsum. The dorsum is separated into the prodorsum and postdorsum by the prodorsal sulcus and the tergopleural interior muscle 2 is inserted dorsally to a small hollow in the postdorsum in Araecerus, Phialodes and Apoderus (Figs. 2, ACD). This hollow develops into a distinct paradorsal sulcus and divides the postdorsum into median and lateral areas in Exechesops and Apion (Figs. 2, BG). The prodorsal external muscle is one and the postdorsal external muscles are three in number in these genera (Figs. 3, Gabc).

In the Rhynchitinae, the dorsal area is subdivided into three folds by two sulci. The prodorsal external muscle and the postdorsal external muscle 1 attach the posterior sulcus and the postdorsal external muscle 2 attaches the anterior sulcus. These facts suggest the possibility that the posterior part of the prodorsum and the lateral area of the postdorsum between two sulci as seen in some anthribids make up the median fold (Figs. 2, EF ; 3, Gc).

The median fold is wider and intervenes between the anterior and posterior folds in the Curculionidae, Scolytidae and Rhynchophoridae examined. In Rhynchaenus and Cionus, the prodorsal external muscle is one and the postdorsal external muscles are three in number, and the transverse sulci are delicate (Figs. 2, HI ; 3, Gd). The other genera of the Curculionidae have well-marked three tergal folds and two prodorsal external muscles. The postdorsal external muscles are three to five in number (Figs. 3, ABFGe).

In Tomicus, the musculature is similar to Curculio except for the arrangement of the postdorsal external muscles (Fig. 3, E).

In Myocalandra, the dorsal muscles are highly developed, and both the prodorsal and postdorsal external muscles are increased in number (Figs. 3, C ; 3, Gf).

The paradorsal tergal area. The lateral part of the posterior fold is separable into the paradorsal tergal area in some cases by the insertions of the tergopleural muscles. But, its dorsal and lateral boundaries are usually indefinite and the mode of the insertions of the tergopleural muscles are variable among the genera examined.

The spiracular area. This area in the abdomen is poorly defined dorsally and well defined laterally by the epipleural sulcus. There are usually one or two oblique sulci from the upper junction to the posterior part of the epipleural sulcus. In Phialodes, one sulcus runs above the spiracle, while in Araecerus, Apion, Tomicus, etc. it runs below the spiracle. Two sulci are present in Curculio including the spiracle between them. Muscles are not inserted into these sulci. 

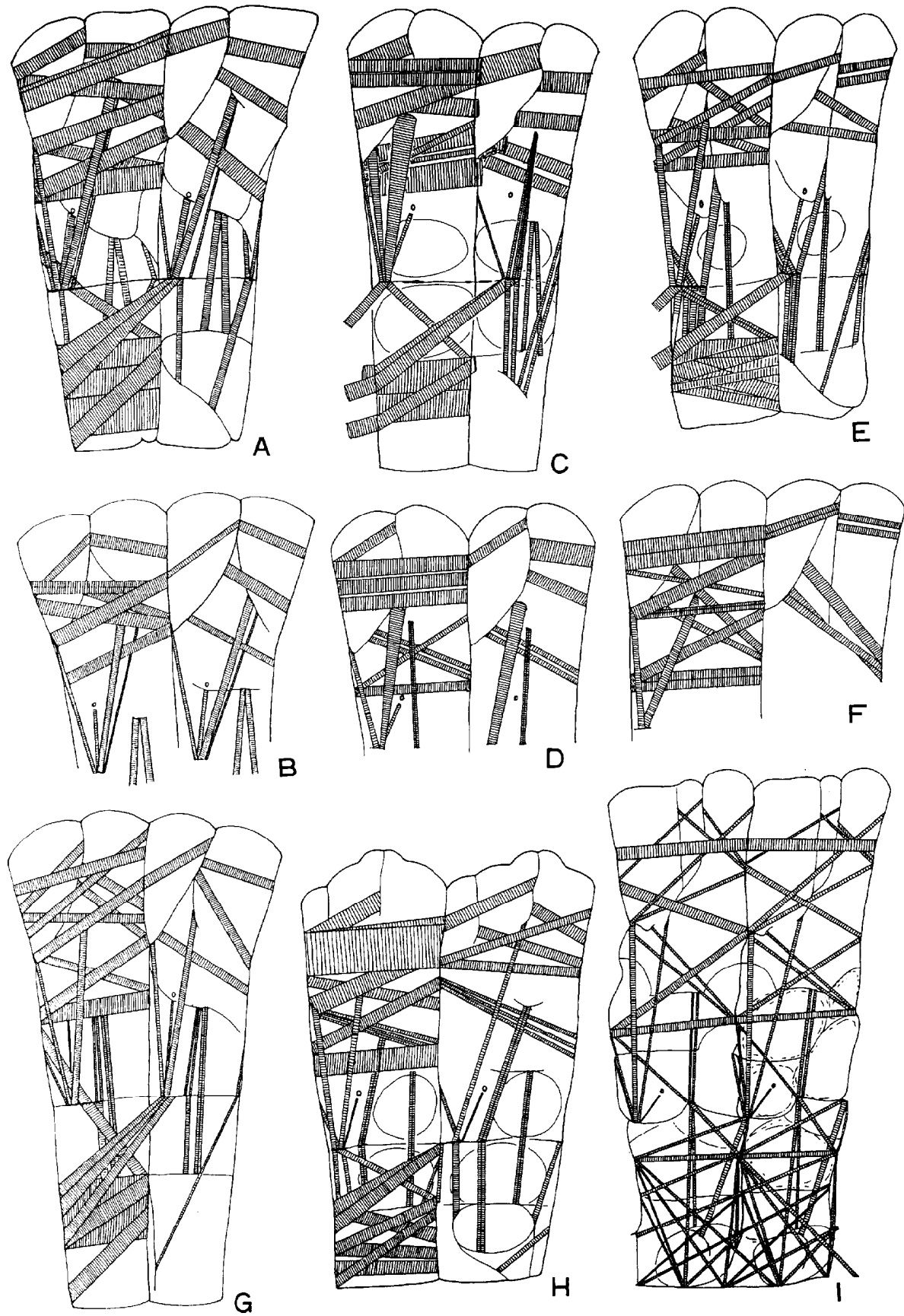

Fig. 2. The muscles of the typical abdominal segments. A :Araecerus fasciculatus. B : Exechesops leucopis. C: Phialodes rufipennis. D : Apoderus nitens. E: Mechoris ursulus. F: Byctiscus venustus. G: Apion japonicum. H : Rhynchaenus horii. I: Cionus helleri. 

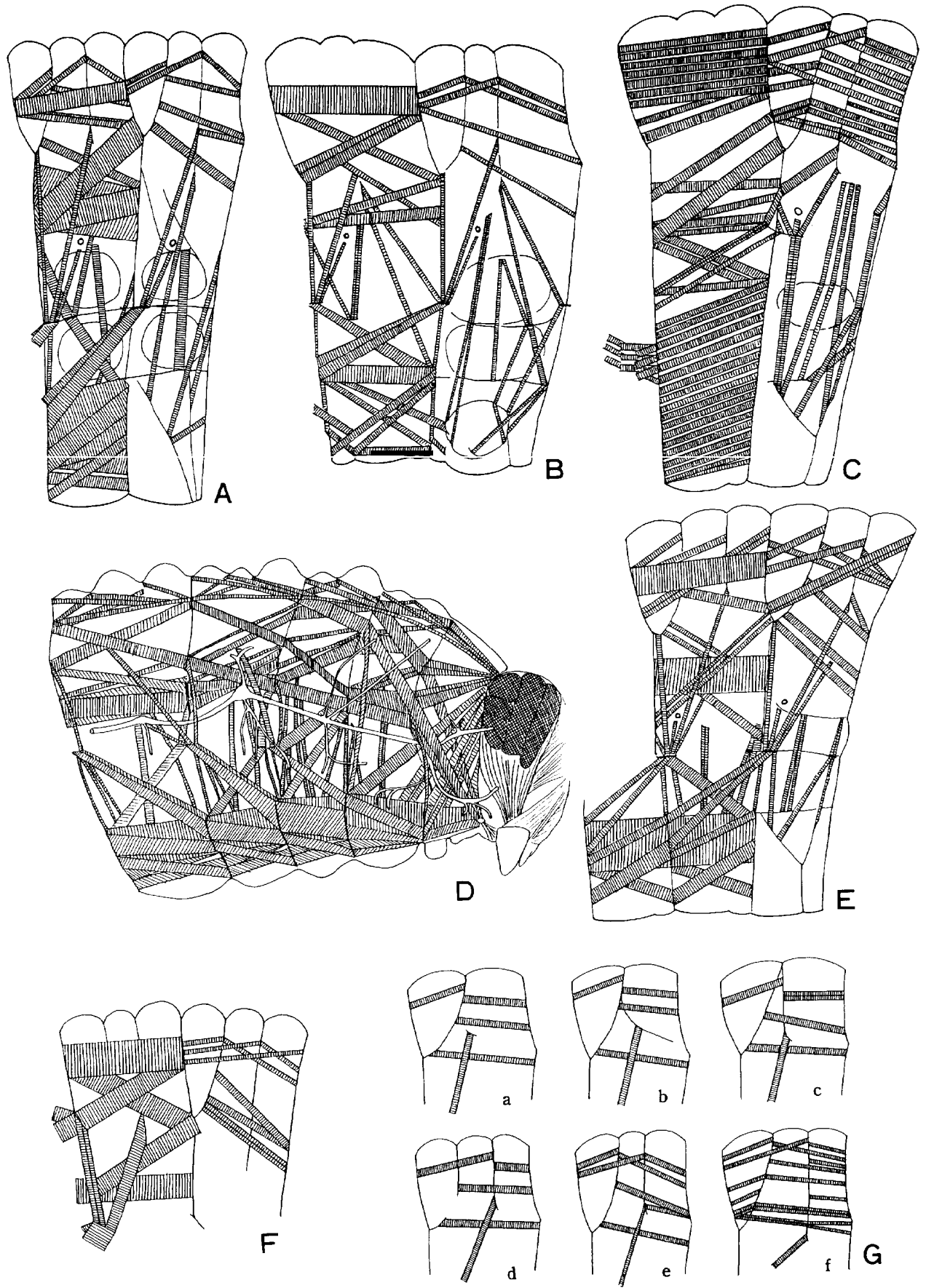

Fig. 3. A, B, C, E, F : The muscles of the typical abdominal segments. A : Curculio dentipes. B : Hypera basalis. $C$ : Myocalandra exarata. D :Curculio dentipes, medial view of the left half. E : Tomicus piniperda. F:Episomus mundus. $G$ : Schema of the tergal folds (a : Araecerus. b: Apion. c: Byctiscus. d:Rhynchaenus. e : Curculio. f : Myocalandra). 
The epipleurum. This is a lateral area of the tergum and limited ventrally by the dorsopleural sulcus and dorsally by the epipleural sulcus. The latter sulcus is defined by the insertions of the tergosternal muscles except for Cionus, in which the latter muscles are absent.

\section{The pleurum.}

The pleurum is a distinct area below the tergopleural, sulcus throughout the body. This area is defined by the presence of a few pleural setae externally, and by the insertion of a diagonal muscle from the anterior part of the tergopleural sulcus to the posterior part of the pleurosternal sulcus. In Myocalandra and other genera of the Rhynchophoridae, the pleurum is subdivided into two or more lobes dorsoventrally. This is probably due to the great increase of the ventral muscles, and not due to the arrangement of the lateral muscles. Their lateral muscles are not different from those of the other groups (Fig. 3, C).

\section{The stemum.}

The sternum is divided into two areas by an oblique sulcus and the sternellum is not developed in the genera of the families Anthribidae, Attelabidae and Apionidae. The sternum is subdivided into three areas and the sternellum is present in the genera of the families Curculionidae, Scolytidae and Rhynchophoridae.

\section{The thorax}

The tergum.

The tergal areas of the prothorax are fused together to a great extent and cannot be clearly homologized with the areas of the pterothorax. The mesothorax and metathorax are similar to each other in structure. The tergum of the pterothorax is subdivided into the dorsum, alar area, spiracular area and epipleurum (Fig. 1).

The dorsum. The dorsum of the pterothorax is divided into the prodorsum and postdorsum by a distinct sulcus.

The spiracular area. The first thoracic spiracle has its place in the forefront of the mesothorax in Anthribidae and Attelabinae, in the intersegmental sulcus in Cylas and Nanophyes, and in the rear of the prothorax in the others. The second thoracic spiracle is absent. The spiracular area of the mesothorax is well defined by the spiracular muscle and usually lies above the epipleural sulcus. It is poorly limited dorsally by a diagonal groove, into which a tergopleural exterior muscle attaches. The spiracular area of metathorax is easily defined by its position as a similar subtriangular area to that of the mesothorax, but the spiracular muscle is absent.

The alar area. The alar area on each side of the mesothorax and metathorax is both delimited dorsally and ventrally by diagonal grooves. These grooves are often indistinct, but clearly defined by the attachment of the tergopleural interior and exterior muscles.

The epipleurum. The epipleurum is usually smaller than that of abdomen and the dorsal border to the spiracular area is often indistinct.

The pleurum.

The pleurum of the thorax is much smaller than that of abdomen. The tergopleural sulcus is more or less sinuate and its rear part is weak in some cases.

The sternum.

The pedal area of the thorax is homologous to that of the abdomen judging from the similarity of their musculatures. The legs are present in the Ithycerus, either present or absent in the Anthribidae and Brentidae, and usually absent in the other families. They are small and sclerotized in some brentids and Ithycerus, but usually not sclerotized in the others. In Curculionidae, fleshy and two-segmented legs are present in Gymnetron, and their traces are observable in each pedal area as a weak oval swelling in many other genera. 


\section{Discussion}

According to Emden(1938), the tergal folds of abdomen are two in the Anthribidae, Attelabidae, Apioninae, Orobitinae, Stenopelminae, Mecininae and Rhynchaeninae, three to four in all other Curculionidae, Brenthidae and Platypodidae, and two or three in Scolytidae. The first character state is considered to be ancestral by Sanborne (1981).

The present study reveals the facts that the Emden's criterion with two tergal folds comprises four character states as schematically illustrated in Fig. 3, G. The anterior fold, prodorsum or the fold I of the abdomen in Anthribidae and Attelabinae is not fully homologous with that of the larvae with three tergal folds. In the Rhynchitinae, the larvae have been classified in the group with two tergal folds, but their prodorsal exterior muscle is inserted into the posterior sulcus and the postdorsal external muscle is inserted into the anterior sulcus so as to form a median fold as shown in Figs. 2, E ; 3, Gc. Thus, the dorsal part of the median fold in the Rhynchitinae, Curculionidae, etc. is supposedly a composite structure from the posterior part of the prodorsum, and the anterior and lateral parts of the postdorsum of the Anthribidae and Attelabidae. The larvae of Rhynchaenus and Cionus have three tergal folds in the abdomen (Figs. 2HI) and the delicate anterior sulcus is probably overlooked by Emden.

Within the limit of our present knowledge, the weevil larvae can be arranged according to their structures of the tergal area in alphabetical order of Fig. 3, G from the simple to complicate character conditions, and the taxa examined in the present study can be grouped into five as shown in Tab. 1.

The alar area and the spiracular area in the thorax are often confusing due to their poor limits. Thomas (1957) did not separate the alar area from the dorsum, and mistook the spiracular area sensu

Table 1. A brief grouping of the taxa examined in the present study.

\begin{tabular}{|c|c|c|c|}
\hline & Pleurum nor & & Pleurum subdivided \\
\hline \multirow{3}{*}{$\begin{array}{l}\text { Prodorsal } \\
\text { external muscle } \\
\text { one }\end{array}$} & $\begin{array}{l}\text { Median fold not differ- } \\
\text { entiated }\end{array}$ & $\begin{array}{l}\text { Anthribidae } \\
\text { Attelabinae } \\
\text { Apioninae }\end{array}$ & \\
\hline & $\begin{array}{l}\text { Median fold differentiated } \\
\text { laterally }\end{array}$ & Rhynchitinae & \\
\hline & \multirow{3}{*}{ Dorsum with three folds } & $\begin{array}{l}\text { Curculionidae } \\
\text { (Rhynchaenus, } \\
\text { Cionus) }\end{array}$ & \\
\hline $\begin{array}{l}\text { Prodorsal } \\
\quad \text { external m. two }\end{array}$ & & $\begin{array}{l}\text { Curculionidae } \\
\text { Scolytidae }\end{array}$ & \\
\hline $\begin{array}{l}\text { Prodorsal } \\
\quad \text { external m. many }\end{array}$ & & & Rhynchophoridae \\
\hline
\end{tabular}

Table 2. A comparison of the terms used for the thoracic areas by several authors.

\begin{tabular}{l|l|l|l|l}
\hline \multicolumn{1}{c|}{ Keifer, 1933 } & Anderson, 1947 & Emden, 1952 & Thomas, 1957 & May, 1977 \\
\hline Prescutum & Prodorsum & Praenotum & Dorsum I & Prodorsum \\
Scutoscutellum & Postdorsum & Postnotum & Dorsum III & Postdorsum \\
Alar area & Alar area & Alar area & Dorsum III & Dorsolateral area \\
Preepipleurum & Spiracular area & Epipleurite & Alar area & Alar area \\
Epipleurum & Epipleurum & Epipleurite & Dorsopleural lobe & Dorsopleurum \\
Hypopleurum & Pleurum & Hypopleurite & Hypopleural lobe & Ventropleurum \\
\hline
\end{tabular}


Anderson as the alar area. May $(1971,1977)$ termed the spiracular setae as the alar setae and the alar setae as the dorsolateral setae. The terms of the thoracic areas used by several authors are compared in Tab. 2.

In the sense of Anderson (1947), the alar area can be defined by the insertions of the tergopleural muscles, and the spiracular area can be by the spiracular and the tergopleural exterior muscles.

\section{References}

Ahmad, M. and H. R. Burke, 1972. Larvae of the weevil tribe Anthonomini. Misc. Publ. ent. Soc. Amer., 8(2): 33-81, 121 figs.

Anderson, W. H., 1947. A terminology for the anatomical characters usuful in the taxonomy of weevil larvae. Pyoc. ent. Soc. Wash., 48: 123-132.

Bbving, A. G., 1954. Mature larvae of the beetle-family Anobiidae. Dan. Biol.Medd., 22(2): 1-298, 50 pls.

— and F. C. Craighead, 1930. An illustrated synopsis of the principal larval forms of the order Coleoptera. Ent. Amer., XI (n. s.) : 1-348, 125 pls.

Emden, F. van, 1938. On the taxonomy of Rhynchophora larvae. Trans. Y. ent. Soc. Lond., 87 : l-37, 107 figs.

Gardner, J. C. M., 1934. Immature stages of Indian Coleoptera. Ind.For. Rec., XX : 1-48, 6 pls.

Keifer, H. H., 1933. Some Pacific coast Otiorhynchid weevil larvae. Ent. Amer., XIII (n. s.) : 45-85, pls. XVI-XXVI.

May, B. M., 1971. Entomology of the Aucklands and other islands south of New Zealand : Immature stages of Curculionoidea. Pacific Ins. Monogr., $27: 271-316,162$ figs.

- 1977. Immature stages of Curculionidae : Larvae of the soil-dwelling weevils of New Zealand. J. Y. Soc. New Zealand, $7: 189-228,162$ figs,

Morimoto, K., 1970. [Introduction to the study of weevils. II. Larvae.) Nature and Insects, Tokyo, 5 (1) : 30-34. (in Japanese)

Sanborne, M., 1981. Biology of Ithycerus noveboyacensis (Forster) and weevil phylogeny. Evol. Monogy., 4: 1-80, 209 figs.

Thomas, J. B., 1957. The use of larval anatomy in the study of bark beetles. Canad. Ent., Suppl. V : 3-45, 105 figs. 